\title{
7 \\ The welfare of future generations
}

In Chapter 7 we examine one of the many possible links between sustainability and distributive justice (B. Barry, 1999). For instance, we could look at issues of international justice, i.e. between developed and developing worlds, or we could explore the extent to which the concept of justice is applicable to the non-human world. However, despite the relevance of those debates, the issues of sustainability and justice are thrown into sharper relief by addressing the following question: what does it mean to act with justice towards future generations and what might this imply for social policy?

The debate concerning future generations has generated a considerable literature in recent years, but by no means everyone is convinced that justice towards future generations makes sense. Of the sceptics, the most cogent recent defence has been provided by Beckerman and Pasek (2001: 14) who reduce their argument to a syllogism:

1 Future generations - of unborn people - cannot be said to have any rights,

2 any coherent theory of justice implies conferring rights on people, therefore

3 the interests of future generations cannot be protected or promoted within the framework of any theory of justice.

Beckerman and Pasek are not arguing that future generations should be ignored, merely that when we act with their interests in mind, we can only do so out of benevolence and not as a matter of justice and obligation. The problem with this view is that benevolence is a weak peg upon which to hang the interests of anybody, because it is easier than justice to rationalise away. Although it is certainly virtuous to act with charity, it may be equally virtuous to act without it on those occasions when we convince ourselves that charity would do more harm than good. A theory of justice 
is therefore needed to reveal such instances, and so to ground the virtues of character in more solid foundations than a virtue ethic can provide for itself, to distinguish between in/actions that do and those that do not truly promote the interests of others.

That at least is the premise of the following sections within which I offer the outline of a theory of intergenerational justice and explain what this theory might imply for welfare reform (Fitzpatrick, 2001b, 2001c). In the concluding section I then return to the arguments of Beckerman and Pasek to see whether we can successfully address their main points.

\section{Future philosophies}

A theory of intergenerational justice could be constructed from within a number of philosophical schools. Since the laissez-faire approach of libertarianism is alien to this book's stance, I will leave it to one side and concentrate upon utilitarian, contractualist and communitarian perspectives. Which of these is the most convincing?

\section{Utilitarianism}

The utilitarian approach has been sketched most brilliantly by Derek Parfit (1984: 377) who begins with what he calls the Non-Identity Problem (N-IP): 'If a choice between two social policies will affect the standard of living or the quality of life for about a century, it will affect the details of all the lives that, in our community, are later lived. As a result, some of those who later live will owe their existence to our choice of one of these two policies. After one or two centuries, this will be true of everyone in our community'. In other words, it is impossible for us to harm future generations. Imagine two policy options: policy $R$ will give rise to Red people, while policy $B$ will give rise to Blue people. If we choose policy $R$, will we be hurting anybody? According to the N-IP we will not. We cannot harm any Blue people, since they will now never exist, and we cannot harm our Red descendents because their existence is axiomatically preferable to the non-existence that would have resulted had we chosen policy $B$. Now think of a parallel scenario. Policy $D$ leads to the depletion of natural resources and so to future generations whose lives are barely worth living; policy $C$ leads to the conservation of resources and so to future generations whose well-being is comparable to our own. If the N-IP is correct, then we may as well choose policy $D$ (because $C$ requires undesirable short-term sacrifices) without worrying about the consequences. In short, if we cannot harm future generations, then we cannot act with injustice towards them and so cannot act with justice 
towards them either. No theory of intergenerational justice is therefore possible.

Parfit himself suspects that the N-IP can be overcome with reference to some objective standard of assessment. However, in searching for this standard Parfit (1984: 388) encounters the Repugnant Conclusion: 'For any possible population of at least ten billion people, all with a very high quality of life, there must be some much larger imaginable population whose existence, if other things are equal, would be better, even though its members have lives that are barely worth living.' Imagine two societies. In society $A$, ten billion people each possess 100 utility units each (or 1000 billion units in total); in society Z, 2000 billion people each possess 1 utility unit each (or 2000 billion units in total). On strictly utilitarian grounds we ought to prefer society $Z$, because 2000 billion units is larger than 1000 billion units, even though its inhabitants live lives of unimaginable suffering. Therefore, utilitarianism seems to demand the indefinite growth of future populations so long as total utility increases also. Few would regard this as desirable and yet Parfit insists that attempts to avoid the Repugnant Conclusion are inadequate (e.g. BooninVail, 1996).

Let us consider two such attempts. First, perhaps we could adopt a principle of average rather than total utility. This would imply that we should only permit the human population to increase to the point where mean utility begins to peak, i.e. a point significantly less populated than society Z. Yet Parfit dismisses this escape route, as it would prevent us from adding to the population those individuals who, although they would have lives worth living, would reduce the overall average. Second, perhaps we could place a ceiling on the population's expansion on the grounds that, beyond a certain point, the value of additional utility diminishes at an ever-accelerating rate. Yet Parfit closes off this escape route also, by observing that if we devalue additional utility then we are logically compelled to devalue additional disutility, i.e. the equivalent of being increasingly untroubled at a society where there was more and more pain and suffering.

However, there is a third argument for avoiding the Repugnant Conclusion, one that questions the N-IP upon which it is based, but which Parfit himself cannot attack because of his utilitarian frame of reference. Carter (2001: 442-8) points out that the N-IP only applies at a holistic level that ignores more specific actions: ' . . . even if I were able to affect the identity of every person in the distant future, it would not follow that I could not harm any of them. I could still harm a future person whose identity I determined as long as one of my actions made him or her worse off than he or she would otherwise have been - in other words, as long as that action was not one which determined his or her identity'. In short, 
acts of identity creation are not necessarily identical to acts of harm and so it is possible to harm those who we have brought into being, even if there is another possible world in which they would never have existed at all. What exists in the gap between acts of identity creation and acts of harm? Autonomy. And so how would we harm future generations? By reducing their capacity or willingness to act with autonomy and independence.

But by collapsing 'welfare' into 'utility' and, like all utilitarians, by downplaying the concept of autonomy, Parfit does not have recourse to this solution, suggesting that a utilitarian approach does not offer a convincing approach to the problem of future generations. If we take the objective of harm avoidance seriously, then our task cannot be measured by a utility index and we do not have to decide between an infinite range of future identities. For a utilitarian like Parfit, an infinite range of future identities is possible and therefore we cannot harm future generations. But if we recognise instead that we harm future generations by reducing their autonomy to levels that we ourselves would not accept, then the range of possible identities is not infinite, but is limited to those that imply self-determination. Therefore, environmentalists are right to suspect that we harm future generations by bequeathing to them an unsustainable environment that would reduce their powers of selfdetermination by diverting resources and energies away from autonomyenhancing pursuits. Of course, future generations may use their autonomy to wreck the environment that we will (hopefully) bequeath But this is a perpetual risk best overcome by principles of justice that it would be irrational and so unjust of future generations to ignore (see below).

If utilitarianism fails, then is there a better approach?

\section{Contractualism}

Rawls (1972: 284-93; 1999: 145-7; B. Barry, 1989: 197-201; Hooft, 1999; Langhelle, 2000) introduces into the original position an ignorance as to where the participants are in history, meaning that they have to determine a savings rate that every actual generation would find to be just. In effect, all future generations are represented in the original position and all can expect to gain through the 'just savings principle', with the exception of the first generation who shoulder the initial burden, but receive nothing in return. However, because each generation is assumed to care for its immediate descendants, the first generation, too, can be expected to accept the just savings principle. This means that the task of each generation is to realise the demands of liberal justice while contributing to an intergenerational process of accumulation that enables closer and closer 
approximations to the just society which is contracted to in the original position.

The notion of 'immediate descent' is crucial in actually determining the appropriate rate. Those in the original position must ask themselves how much it is reasonable to save for the next generation, based upon what they feel entitled to claim from the preceding generation. This parent/child model not only enables a fair rate of saving to be determined, but ensures that no generation can envy the stock of resources possessed by either its ancestors or its descendants. Consequently, although the members of the original position do not know where they are in time, they do know that they are contemporaries who have sentimental ties to successive generations. Basically, then, a contractualist theory of justice must take into account the least advantaged of every generation: 'Whereas the first principle of justice and the principle of fair opportunity limit the application of the difference principle within generations, the savings principle limits its scope between them. ... Saving is achieved by accepting as a political judgement those policies designed to improve the standard of life of later generations of the least advantaged, thereby abstaining from the immediate gains which are available' (Rawls, 1972: 292-3). It means that duties are inter- as well as intragenerational and that we harm future generations if we bequeath to them conditions that we ourselves would not consent to in an original position.

By giving priority to liberty and rational determination, this approach takes harm avoidance seriously and so seems to overcome the problems inherent within Utilitarianism. There are two main problems with Rawls's account, however. First, it is arguably too ambitious in its stipulation that the participants in the original position may be located anywhere in time. To totally exclude the particulars of our temporal situations from considerations of justice would seem too abstract and formal an approach. Of course, Rawls then inserts a discount rate, but one which is far too stringent, extending across no more than two future generations. So the second problem is that the just savings principle is not ambitious enough, having the quality of a personal inheritance made through ties of sentiment rather than a true cross-generational scheme of accumulation. Therefore, Rawls's theory of intergenerational justice is both too abstract and too sentimental. Let us begin with the second problem.

Can we resolve this difficulty by (a) including all generations within the original position (so that the participants are not contemporaries), and (b) eliminating the sentimental motivation? The problem with (a) is that it runs up against a version of the N-IP. Do we include everyone who will ever live? Yet this presupposes an advanced knowledge of the policies and principles that we are to adopt when it is precisely those policies and principles that we are trying to formulate. But perhaps we can include in 
the original position everyone who could ever live. Yet how would it be meaningful to include in the original position anyone who is being called upon to possibly legislate themselves out of existence (Carter, 2001: 440)? Such participants may well prefer something resembling the Repugnant Conclusion as a necessary price of their continued existence. Therefore, critics have demanded that we fall back on (b). Brian Barry (1989) argues that Rawls's Humean influences must be discarded, as justice cannot be founded upon the sentimental ties that we have for our successors and Rawls (1993: 274) himself came to accept this. For Barry then, Rawls is formulating principles to which all generations should rationally agree, what we might call a theory of 'meta-generational justice'.

However, this still leaves the objection that Rawls is being too ambitious. I think we can address this problem by acknowledging that although it might be the case that justice cannot be founded upon sentiment, this does not mean passion and sentiment are irrelevant to considerations of justice (see Chapter 6). In short, we have yet to consider communitarian critiques of intergenerational justice.

\section{Communitarianism}

Avner de-Shalit (1995) has offered a communitarian account, one that essentially depends upon hypothesising the existence of a transgenerational community. If communities are spatial entities, then it seems absurd to deny that they are also temporal entities; and if communities are the most important source of identity and obligation, then the future must be an important source of identity and so a referent to which I bear obligations. As Dobson (1998: 105) points out, de-Shalit is here echoing O'Neill's (1993: 28-38) depiction of the transgenerational self. For although I, the being now in existence, cannot be harmed 50 years after my death, my reputation and my legacy can be damaged. Similarly, then, not only can the present generation harm future ones, but future generations can harm us and we can harm long-dead generations! Therefore, there may well be a loose reciprocity between generations that grounds the notion of intergenerational justice after all.

The problem here, though, lies in determining the criteria by which harm can be assessed. When past generations burned witches or initiated pogroms they no doubt genuinely believed that their legacy would benefit their descendants. Are we harming past generations by dissenting from such beliefs, therefore? To believe so is equivalent to believing that our ethical standards should be equivalent to theirs, which is nonsensical. Instead, it seems that although past generations can harm us (intentionally or otherwise), we cannot harm the past by choosing to betray their legacy. Therefore, although there is a transgenerational community that 
points into the future, there is none that points into the past; we can form a community with our descendants but they cannot form one with us, nor can we with our ancestors. We can harm the future, but the future cannot harm us.

It is at this point that the critics of intergenerational justice step in and say something like the following. Justice implies reciprocity and reciprocity is, of its very nature, a two-way process: if the future cannot harm us then we cannot harm it. Can this objection be met? I believe so. The essential question concerns who is being harmed. I have already argued that we harm the future if we do not bequeath to them an environment that is consistent with levels of autonomy that we ourselves would accept. But imagine that we do bequeath that environment and future generations use their autonomy to wreck it. Are we harmed by this? No, because we are no longer around to feel harm. But this does not mean that harm is not occurring. For if the future does wreck that environment, then they will be harming their descendants by undermining their autonomy by betraying not us but the principles of inter- or meta-generational justice that we are formulating. Similarly, if we suddenly decided to abolish free societies we would not be harming Immanuel Kant et al., but we would be harming a future that would have to struggle to regain the autonomy that we chose to waste.

What this indicates is that although reciprocity is a two-way process, this process is not erased by time's arrow (B. Barry, 1999). We often help others without an expectation of either direct or indirect return, not as an act of benevolence (because we are nice people) but because it is the right thing to do (because we recognise the demands of justice, whatever the implications for ourselves). To claim (a) that we cannot harm the future implies (b) that we cannot have been harmed by the past and furthermore (c) that we have not been benefited by the past. It is to claim that justice cannot exist unless we can experience the reciprocal consequences of acting justly. But if (b) and (c) are patently false then (a) must be false also. Therefore, across the temporal dimension reciprocity may resemble what Ball (2001: 103-4) calls serial or 'punctuated reciprocity', where each generation recognises an obligation to act with justice towards its descendants according to the demands of inter- or meta-generational justice that it would be irrational to ignore.

This is one of the reasons why in Chapter 2, I was so concerned to challenge the simplistic 'rights imply responsibilities' chant of new social democrats. For, when applied to this debate, that insistence might imply that we have no obligations towards the future because they have no rights at the present time. This is the position of Beckerman and Pasek. But if what we are doing is formulating a theory of meta-generational justice, then this simplistic equation does not hold: rights may imply 
responsibilities, but not necessarily on each and every occasion. So, even though future generations are not around to make claims on our energy and resources, we might still have obligations towards them based upon a theory of justice to which all generations should rationally assent. Therefore, punctuated reciprocity is one facet of the kind of diverse reciprocity that I spend the latter part of Chapter 2 defending.

For Goodin (1985: 177-8) those obligations derive from the unilateral power that we hold over our descendants, their vulnerability in relation to ourselves. Unlike de-Shalit, however, Goodin allows sentimental ties to supplement rather than replace the contractarian approach. Once we remember that, for Rawls (1972: 50; 1993: 3-46), the original position is a site of 'reflective equilibrium', and political rather than metaphysical, then our concern for the vulnerable is permitted to creep beneath the veil of ignorance. So we find a middle way between the overand underambitious sides of Rawls's just savings principle. The original position should not be located anywhere in time since, as I argued in Chapter 6, rational universalism must be context-sensitive (see below); but nor are its inhabitants concerned only with their offspring since although justice may make room for sentiment, it cannot be based upon sentiment.

In short, a convincing theory of intergenerational justice has to balance partiality and impartiality with reference to the particular (the established and imagined needs of the present and future, respectively) and the universal (the just savings principle). It is a contractualist theory tempered by elements of communitarianism and so derives from the kind of deontological reasoning that I defended in Chapter 6, a reasoning that makes room for a pragmatic turn towards context-sensitivity. And since, given the ecological constraints we now face, sustainability must now be placed at the heart of all such policies, then it follows that sustainability is the principal means of effecting justice across the generations.

\section{Discount rates}

However, if we are to have a clearer idea of what intergenerational justice means and implies, then we have to possess some idea of the relevant timescale, i.e. the temporal context to which our theory is sensitive.

Technically, discounting refers to the means by which we gradually devalue future costs and benefits against, respectively, present benefits and costs (Lind, 1982; Portney and Weyant, 1999). At one extreme, we can imagine a refusal to discount at all, so that the interests of people, say, a million years from now would mean as much to us as our interests - we will call this a discount rate of 0 per cent; at the other, we have a refusal 
to value the interests of any generation but our own-we will call this a discount rate of 10 per cent. ${ }^{1}$ How are we to determine a discount rate which, lying between these extremes, is both practical and desirable? By and large, two answers have been given to this question.

First, there are those who favour a market discount rate. A benefit-cost analysis focuses upon the real rate of return on investment over a particular time horizon. What this implies is the use of real interest rates in calculating the discount rate and a 'private time preference' in which the time horizon is relatively short. The problem with this method is that the medium- to long-term future is discounted fairly heavily (Amsberg, 1995). For instance, let us imagine that an asteroid is passing close by which, during its next orbit in 200 years time, will hit Florida (Nordhaus, 1999: 148). If the damage is estimated at $\$ 2$ trillion at today' prices, and if we apply a 7 per cent per year discount rate (a rate sanctioned by the US Government), then it is not worth us currently spending anything more than $\$ 3$ million in trying to save Florida 200 years from now!

Therefore, a second method defines a social discount rate where equity and fairness are as important as efficiency. This 'social time preference' looks farther than the lifespan of individuals and so favours a lower discount rate. For example, public sector projects tend to apply a social rate because governments can borrow at lower interest rates than those offered to private sector investors and because the risks attached to the investment are lower. The problem with this method is that the calculation of the actual rate becomes more a matter of prescriptive guesswork regarding the desirable distribution of costs and benefits across different generations (Cowen and Parfit, 1992).

The debate over discounting returned with the growth of environmental economics in the 1990s. If we set a discount rate that is too high (profligacy), then we might not be able to create and maintain a sustainable ecosystem; if we set a rate that is too low (asceticism), then the present generation may be called upon to make sacrifices that are politically and culturally unrealistic. Is there an alternative? A complication in finding an alternative involves what we might call the 'savings paradox'. Since material well-being has improved throughout recorded history, it seems reasonable to assume that the future will be materially better off than the present. Therefore, saving for the future by reducing present expenditure will only increase the gross wealth of the future, at a cost to the present, and so undermines the rationale for saving; however, if we do not save for future sustainability by reducing present consumption, then although the future may be materially better off, it will have to spend a far higher proportion of its wealth on environmental protection, thus increasing the rationale for saving. Is there a way around the savings paradox that allows us to determine an appropriate discount rate? 


\section{Sustainable justice}

The real problem with the paradox may be it operates with too narrow a conception of savings, investment and consumption. If these are conceived in terms of resource depletion then, because resources are ultimately finite, we are certainly left with a conflictual model of intergenerational relations: more burdens today means more benefits tomorrow, and vice versa (Schelling, 1995). Even if we assume a positive sum game, where the wealth of both the present and future can be simultaneously enhanced, any economy based upon resource depletion must make trade-offs between present and future needs; technological fixes and the like can postpone the trade-offs, but cannot avoid the conflictual model itself. In short, resource depletion gives rise to intergenerational conflict. But what if we base our environmental economics less upon depletion and more upon resource transformation? If what we consume are finite resources, then higher savings may well imply lower consumption, and vice versa; but if what we consume, i.e. enjoy as essential to our well-being, is the preservation of resources and the flourishing of the non-human then higher savings might well be a condition of higher consumption. So, the savings paradox is avoided by replacing a material with non-material conception of well-being (Tacconi and Bennett, 1995: 218), i.e. one that respects reproductive values (see Chapters 4 and 5). To see what this means let us return to our ascetics and profligates.

Ascetics favour a high-low approach, i.e. high savings plus a low discount rate; profligates favour a low-high approach, i.e. low savings plus a high discount rate (cf. Dahle, 1998; Neumayer, 1999). Since asceticism seems to be far closer to the non-material ideal, should we choose a highlow approach as our principle of sustainable justice? If we could instantly transport ourselves into an economy based upon resource preservation, that answer might well be yes. The problem is that it would be inconsistent to ignore the hows and whys of transition from one type of economy to another. To put it simply, pragmatics and political expediency might require a more moderate principle of sustainable justice, tying in with the arguments sketched in Chapter 6.

So an alternative is a low-low approach where the discount rate is low but so, in the short-term at least, is the savings rate. The rationale here is to apply a low discount rate in order to effect the ethical revaluation, which in the course of time would alter collective notions of savings and consumption (along the lines suggested above) and permit the economic transition which is crucial; in the interim, we have to work within an economy of resource depletion which may well mean not asking people to make burdensome sacrifices. If social and environmental sustainability 
become associated with grim austerity (as anti-environmentalists hope they will), then the case for social and environmental (or sustainable) justice will be defeated. If, however, sustainable justice can be established as meaning not less investment, consumption and spending but different ways of investing, consuming and spending, then the Green argument can become a new orthodoxy. This means that we have to both count the future (low discount rate) and discount it (low savings rate) at the same time.

Before misunderstanding sets in, though, let me add an important qualification. While I am advocating a low savings rate, the rate I have in mind would still be higher than the one which currently prevails. So although it is wrong to assume that the road to sustainability is paved with the ruins of a consumer society, it is the case that Green consumption implies less overall consumption than current levels.

Does a low-low approach satisfy the contractualist theory defended above? Rawls was criticised because he (a) locates the original position anywhere in history, and (b) specifies that participants all belong to a single generation. By contrast, sustainable justice allows the participants to know approximately where they are in history, i.e. their decision is context-sensitive, while including within the original position all representatives from within that time horizon, i.e. they hold weak ties of sentiment to their near contemporaries rather than strong familial ties to their children. Let us assume a horizon of 200 years stretching from 2000 to 2200. The participants know this, and are therefore aware of what is at stake environmentally, though none of the individuals know where they themselves belong. Individuals are unlikely to advocate profligacy, in case they should find themselves in an environmental wasteland of later generations; though nor is asceticism likely to be popular as this imposes draconian sacrifices on earlier generations. So, a low-low approach seems like a reasonable compromise, in that all generations are valued (low discount rate), but earlier generations are permitted to use and transform the world's resources so long as, in doing so, they improve both the condition of the ecosystem and humans' ability to appreciate reproductive values.

If these assumptions are correct, then we are left with principles of sustainable justice that include:

1 intragenerational equity (see Chapter 2);

2 intergenerational equity (just savings, autonomy and diverse reciprocity);

3 the question of transition;

4 the ethic of reproductive values.

So although (1) and (2) do not necessarily lead to a conflictual model, (3) suggests that some conflict cannot be avoided though it can be smoothed 
out over time with reference to (4). If welfare means GDP growth then, given finite resources, there are trade-off decisions to be made regarding the distribution of sacrifices, i.e. between (1) and (2). But if, as Chapter 5 argued, even Green versions of GDP are stages towards an ISEW, then the issue of trade-offs become less urgent, e.g. the future's enjoyment of the natural environment is not reduced by our enjoyment of the same, and vice versa. We make all generations wealthy by placing environmental public goods at the heart of what we mean by wealth. Nevertheless, the problem of transition means that the question of trade-offs cannot be avoided entirely and for any theory of justice this means taking account of the poor. Can we square the circle of assisting both the present and future poor?

\section{Two rules}

The problem is this. Poverty, inequality and injustice currently exist at levels that few regard as desirable. Poverty bears an environmental dimension, since the poorest are those most likely to suffer from ecological degradation. However, although many anti-poverty policies will be environmentally benign, and many pro-environment policies will reduce poverty, the conjunction between social justice and environmental sustainability is by no means total. Some anti-poverty policies may need to be environmentally damaging, e.g. a dash for GDP growth, and some proenvironment policies may be detrimental to the poor, e.g. price rises on scarce resources. The question is, when are such trade-offs acceptable?

In this respect, therefore, I am agreeing with Dobson's (1998) thesis that justice and sustainability are contingently rather than necessarily related (cf. Langhelle, 2000). Dobson's seminal treatment of the subject, Justice and the Environment, will therefore be a key source for what follows. Dobson, though, neglects the policy aspects of this subject. Although the relationship between justice and sustainability may always remain contingent in a philosophical sense, it is also true that if we manage to design policies which strengthen that relationship, then the non-conjunction of antipoverty and pro-environment strategies may eventually fade to insignificance. However, in order to design such policies, we first need to understand when poverty reduction might be allowed to trump sustainability and vice versa. Of course, much will ultimately depend upon the particular circumstances within which such judgements are made, yet Dobson is wrong to believe that this is always a matter of empirical determination.

In other words, we can devise general rules which allow such determinations to be made with greater assurance than otherwise. Let me state what I consider these to be. 


\section{The Non-Futility Rule}

Principle $x$ should not be allowed to trump principle $y$ when, under particular circumstances, doing so would be self-defeating.

Let us imagine ourselves making poverty reduction the priority. We might, for instance, make efforts to vastly increase global GDP in such a way that the developing world has access to the consumerist living standards that are still largely confined to developed nations. The problem is that the environmental costs of an extra 2-3 billion cars, refrigerators, computers, etc., would be so great that the advantages of that strategy would be confined to several decades at best. Of course, we can also envisage technological innovations and some sustainability measures lengthening such a time horizon, yet only an economic/technological determinist could imagine ecological crises being forestalled forever. According to the Environmental Kuznets Curve (EKC) economic growth only produces environmental deterioration in its early stages, this being superseded by improvements in environmental quality later on (Panayotou, 1995). However, even if the EKC applies to some pollutants in some geographical localities (Perrings and Ansuategi, 2000), it is dangerous to generalise this hypothesis, as it takes no account of the exponential deterioration of environmental quality on a global scale that can be expected to occur before the zenith of the EKC, e.g. the greenhouse effect. Of course, it is possible to envisage developed countries on the right side of the curve assisting those on the wrong side (Panayotou, 1997), but developed nations have so far demonstrated little inclination to do so. This may be because they are not yet on the right side, obviously, but this only returns us to the dilemma of exponential degradation. In short, those who treat GDP growth as a panacea (e.g. Neumayer, 1999) tend to assume that future environmental deterioration will not differ significantly from present deterioration.

Let us now imagine making sustainability the priority. The problem is that global inequality has doubled over the last 40 years (UNDP, 1996) to a level that is damaging to sustainability (Stymne and Jackson, 2000). This is first because those at the bottom overconsume resources as a means of trying to catch the affluent and perform environmentally damaging practices as a side effect of coping with their deprivation. Of course, many environmental-benign practices are carried out by those with scarce resources, but it is clear that developing countries do not appreciate being told to develop sustainable economies by affluent nations who seem unwilling to take more than modest steps in the same direction. Second, therefore, inequality encourages those at the top to overconsume resources as a means of maintaining their relative position and so to pollute in greater proportions also. Consequently, sustainability that does 
not attend to the injustice of global inequalities will not be effective, remaining at the level of carbon sinks and tradable permits that, for the US Government in particular, are an excuse to maintain its environmentally damaging activities.

However, the Non-Futility Rule does not disallow all attempts to permit one principle to trump the other:

\section{The Deferred Enhancement Rule}

Principle $x$ is temporally allowed to trump principle $y$ when, under particular circumstances, doing so allows the objectives of principle $y$ to be met more effectively in the medium-term than would otherwise be the case.

There are two circumstances to which this rule might apply. First, when inequality is at levels so extreme that priority must be given to justiceenhancing policies. This is obviously so when we are faced with examples of severe deprivation, e.g. famine, but it also follows in cases falling short of such examples, e.g. when income inequality is so great that no moral consensus regarding sustainability can be expected to emerge (or, to put it bluntly, why should the poorest change their activities in order to save a planet ruined by the affluent?). Second, when environmental degradation is so acute that the ecological necessities of life are placed in jeopardy. We can think of these two circumstances in terms of a Titanic metaphor. If the ship is at risk of sinking because the steerage passengers are rebelling, then this has to be the priority - no matter how many icebergs are around! If the ship is about to hit an iceberg, then we had better manoeuvre out of the way and worry about the passengers later on.

However, in both instances we are not defending a principle (either equality or sustainability) for the sake of it, but in order to augment and strengthen the other principle in the longer term. Where injustice is the problem, then egalitarianism and justice enhancement are appropriate responses only until the point where the Non-Futility Rule begins to apply, i.e. the point at which further equality and justice without sustainability would be self-defeating. Under these circumstances, it is an initial equal weighting of justice and sustainability which would be ineffective, so that the latter is better served in the long run by being temporarily deferred. Where the problem is ecological crises, then strategies to enhance sustainability are the appropriate response only until the point where such strategies would be self-defeating without greater equality. Here again, an initial equal weighting would be ineffective, so that justice and equality are better served by being temporarily deferred. Therefore, the Deferred Enhancement Rule is the means by which we create cir- 
cumstances in which the Non-Futility Rule begins to apply; or, to put it more simply, justice can only trump sustainability, or vice versa, if the objective is to allow the two principles to eventually converge. So, we can see that although there is no necessary relation between justice/equality and sustainability, such that we cannot realise one just by realising the other, the contingent relationship is very close nevertheless.

However, we are still left with the problem mentioned earlier: should we prioritise the needs of the present poor above those of the future poor? Are we any nearer to answering this question? Well, yes and no. The NonFutility and Deferred Enhancement rules both suggest that we cannot ultimately have greater justice/equality without greater sustainability and vice versa. If so, then the policies which are most suitable for the present poor will closely resemble those most suitable for the future poor, i.e. policies that come under the heading of sustainable justice. As such, the real conflict may not be between present and future but as always between Left and Right. If we decide that we want a Leftist approach, then decisions over the temporal distribution of benefits and burdens, while important, are of secondary consideration. In short, to characterise the debate in terms of irreconcilable interests between present and future is to reify it and overlook the fact that the main division remains ideological, whatever the precise time horizon involved. Indeed, to neglect the idea that the present and future poor are part of the same moral community might only hand the theoretical initiative to the Right by encouraging the Left to ignore the temporal dimension of social justice. By contrast, the Left must recognise that the road to intergenerational equity is through intragenerational equality.

\section{Ecosocial property}

Having brought ourselves to this point then, we are obliged to say something about what the most appropriate policies might be and how present and future can be woven into a non-zero sum game. What kind of welfare policies synergistically serve the interests of both present and future poor? A useful entrance into this debate is provided by Dobson $(1998,1999)$. According to Dobson, we can identify three main conceptions of environmental sustainability, each of which engenders its own unique account of social justice and the relationship between justice and sustainability.

Conception $A$ (Dobson, 1998: 41-7) is concerned with sustaining the most critical aspects of natural capital, i.e. those aspects which are essential for the perpetuation of human life - the ecosystem, for instance (cf. Benton, 1999). Conception $A$ incorporates an anthropocentric rationale, in 
that 'critical natural capital' is to be preserved for the instrumentalist reasons of protecting human welfare. How might such preservation occur? First, through processes of renewal, e.g. reforestation; second, through the substitution of non-renewable critical natural capital, e.g. substitutes for oil; third, through the conservation of critical natural capital that is non-renewable and non-substitutable. Conception $A$ states that the needs of future generations must override the wants of the present generation, a prioritisation which allows the interests of the non-human to be accounted for also.

Conception $B$ (Dobson, 1998: 47-50) is concerned with sustaining those aspects of the natural world whose loss would be irreversible. In short, while conception $B$ acknowledges the importance of human welfare, it also wants to preserve those elements of non-human nature which risk disappearing forever, even when this loss might not impact upon human welfare at all. Therefore, conception $B$ states that renewability is far less important than substitutability and conservation, since once a species is extinct it cannot, by definition, be renewed. However, there are also limits to the extent to which human-made capital can substitute for natural capital, e.g. an extinct species cannot be artificially recreated. Consequently, this conception gives priority to the needs of present generations of non-humans over the needs of future generations of humans, on the grounds that the loss of a non-human species cannot be justified in terms of the potential benefits of that loss to future generations.

Conception C (Dobson, 1998: 50-4) identifies an intrinsic value to nature, the sustainability of which cannot therefore be measured in terms of human welfare. Of course, the former may enhance the latter, but enhancing the latter cannot be the motivation for the former. Conception $C$ abandons renewability and substitutability, since intrinsic natural value is lost in both instances, and concentrates upon conservation as the main instrument of sustainability. So although conception $C$ does not necessarily want to abandon the prioritisation of human needs, it does want the profile of non-human needs to be raised within the calculus of policy-making.

Each of these conceptions corresponds to a broad 'menu' of ideas relating to social justice. These correspondences are too complex to summarise here, but we can outline the main features. Conception $A$ (Dobson, 1998: 87-164) seems to require the just distribution of critical natural capital, i.e. distribution according to universal needs. This means that critical natural capital cannot be sustained simply by attending to just social relations, as such justice might require the depletion of critical natural capital. Therefore, both the existing pattern of ownership and our ideas about property rights need to alter, perhaps around some notion of environmental space, the distribution of which would have to be global and egalitarian. Con- 
ception B (Dobson, 1998: 165-215) points in the direction of a Green communitarianism, such that justice must involve a broader interpretation of the moral community than that permitted by anthropocentrism and one moreover which is concerned with a single definition of the good (the sustainability of irreversible nature) rather than procedural neutrality between competing definitions. Conception $B$ though is less clear than $A$ regarding the just distribution of natural resources since distribution is functional for sustainability. With conception C (Dobson, 1998: 216-39), however, the link between environmental sustainability and social justice possibly breaks down altogether. At best, sustainability demands whatever pattern of distribution is most likely to produce benign consequences for the environment, and if this ever required social injustice, then so be it. Intrinsic natural value cannot be interpreted as a distributive resource precisely because it is intrinsic. Dobson (1998: 242-67) concludes with a discussion of whether there can be a theory of social justice that incorporates notions of environmental sustainability from across the three conceptions. He accepts the argument of Norton (1991) that a 'future generationalism' might be the means of producing consensus across the Green movement and between Greens and those non-Greens who are concerned with justice to others.

I am not convinced of the merits of this approach however, due to a possible criticism that Dobson himself raises. The problem with future generationalism is that it focuses upon generalisable human interests and neglects distributional conflicts between rich and poor. Unless we operate some kind of discount rate, then we may leave present generations vulnerable and unless we have some notion of distributional justice, then we leave the present poor especially vulnerable. For Dobson then, future generationism must give precedence to those generations closest to us in time. While agreeing with this prioritisation, it seems to me that it fatally weakens future generationalism as conceived by Norton and revised by Dobson. For if we must possess some principle of social justice in order to resolve both intra- and intergenerational distributional conflicts over resources, then conception $C$ must be omitted, due to its biocentric emphasis upon intrinsic value, since this emphasis seems to rule out a close link between justice and sustainability. We are therefore returned to the point made earlier (that the future generations debate is a debate between Left and Right long before it is one about present and future), contradicting the idea that focusing upon future horizons enables ideological conflicts to be resolved.

Sustainable justice as I have outlined it therefore maps onto conceptions $A$ and $B$ of Dobson's framework, but that framework does not currently offer a way forward due to its neglect of political ideology. Can we therefore find a way of proceeding which is more profitable than future 
generationalism, i.e. one that enables us to answer the earlier question about serving the needs of both the present and future poor?

Neither conception $A$ nor $B$ seem to be entirely satisfactory (cf. Rogers, 2000). The problem with conception $A$ is its exclusive focus upon critical natural capital, for although this may cover a large part of the natural world, it instrumentalises the relationship between human and nonhuman. Now, to some extent an instrumentalism is appropriate, e.g. we need to repair the ozone layer for our benefit first and foremost, yet it would not seem appropriate to regard the natural world purely in such terms. Since the future well-being of humanity is in no way dependent upon the survival of the blue whale, then the latter cannot be regarded as critical. Of course, it might be that we would lose the pleasure of coinhabiting the earth with such a creature if it became extinct, but this too would hardly be a critical loss and so points beyond an instrumentalist ethic toward conception $B$.

On the other hand, the irreversibility thesis of conception $B$ is too stringent. Although 3-30 species are made extinct every day (Beckerman and Pasek, 2001: 185-6), the disappearance of most of them probably does not affect our survival or sense of well-being at all. Obviously, there comes a point at which the loss of biodiversity is crucial, but biodiversity does not require us to maintain the existence of each and every species, even if this were possible! Therefore, we need to develop guidelines helping us to distinguish between those species whose irreversible loss would and would not be acceptable. This sends us back in the direction of conception $A$.

I am therefore going to leave open the question as to whether we should prefer $A$ or $B$, or whether there is another theory of sustainability and justice which we could develop incorporating elements of both. For our purposes, it seems clear that for policies to be consistent with sustainable justice, the principle of substitutability (which both $A$ and $B$ embody) is crucial.

Neither renewability nor conservation imply any major, direct impacts upon social redistribution, though they obviously bear implications for the environmental conditions of future generations. Substitutables are different, however. Take fossil fuels. There is a very good case for using up the earth's supply of fossil fuels, albeit at a lower and less damaging rate than at present. First, because doing so helps to improve social welfare, at least as measured in a material sense. Second, because despite the aeons it took to create them, fossil fuels have no intrinsic or aesthetic value: there is little point in just having them lie in the ground. Of course, pollution is an undesirable side effect of using fossil fuels, but their conservation would have no value in itself. In short, a substitutable is a good whose utilisation is acceptable, because the sum total of human welfare is raised as a result, but only if an environmentally benign replacement can be 
eventually found that does not reduce those levels of welfare. As noted in Chapter 5, substitution is potentially valuable, though only as a medium-term measure.

However, the process of substitution is not only a technological question, it is also a question of who benefits, i.e. the distributive pattern of the welfare thereby created. Fossil fuels are subject to private ownership across a relatively limited range of countries. This means that the direct benefits of their depletion flow into the bank accounts of a lucky few. I would like to add the following principle to the above definition, therefore:

Goods should only be substituted if the welfare thereby created is subject to an egalitarian distribution.

The logic is simple: the depletion of a substitutable has implications for everyone, therefore everyone should be able to benefit from it on a scale that current property rights do not permit (Sathiendrakumar, 1996: 159). This means initiating as wide a system of ownership as possible, but does this imply egalitarian private ownership or egalitarian collective ownership?

There are those who abhor any suggestion that nature can be commodified (Naess, 1989), i.e. subject to either private or public ownership. For others, commodifying nature, e.g. through a cost-benefit analysis, is the only way of ensuring that scarce resources are preserved (see $\mathrm{O}^{\prime}$ Neill, 1993: 44-82; Sagoff, 1988) and a pricing mechanism is the best means for signalling when and where a resource is undersupplied. But, as argued in Chapters 5 and 6, the ultimate decision is less between commodification and decommodification and more about whether these imply productivist or post-productivist values. So if collective ownership facilitates post-productivism, then it is desirable, whether or not this represents the commodification of nature. More accurately, the commodification of nature through collective ownership is permissible if this is part of a longterm strategy to transform our values away from the productive towards the reproductive and, we might add, any such strategy succeeds or fails depending upon its implications for poverty.

Therefore, the question of deciding between private and collective ownership also becomes less relevant. Think of the property regimes envisaged by John Roemer (1993) and Roberto Unger (1987), i.e. a system of rights where a certain good is held in common, but each individual possess a right to that dividend which is yielded by the utilisation of the good. In what I shall call an 'ecosocial' property regime, individuals are therefore not able to trade or sell the good itself, but they are entitled to a 'rent', i.e. an equitable share of the value produced by the good translated into a monetary income, a share that reverts back to the commons on the death of the individual. This then is a social dividend system of 
which BI would be an initial version (see Chapter 6), a property regime based upon the socialisation of substitutable goods. What this would require is a sophisticated taxation system where destructive utilisation is taxed at a higher rate than those activities which raise the level of sustainable welfare, as measured on an appropriate index. Such taxes (as we argued in Chapter 6) would need to be based upon an ethic of stewardship, for if natural resources are collectively owned, then policies must recognise our role as being that of trustees who have a duty to bequeath to the future a level of critical natural capital that we ourselves would be willing to live with. In effect, this means internalising that which is currently externalised, so whereas GDP growth takes no account of hidden environmental costs, a sustainable welfare index would ensure that these are made fully visible. Green taxes and an ecosocial property regime are therefore dependent upon one another: without the latter, the former simply encourage taxpayer revolts; without the former, the latter would not necessarily be any more conducive to sustainability than the current system of capital accumulation.

To illustrate this second point, we might identify similarities between an ecosocial regime and what Blackburn $(1999,2002)$ calls the 'new collectivism' (Aglietta, 1998; Self, 2000). Blackburn, like Druker (1994, 1996) before him, spies a radical potential in the shift to pension-fund capitalism, with pension funds now totalling some $\$ 13,000$ billion. If such funds were democratically controlled by the policyholders themselves and invested in equities and bonds, then substantial portions of the economy could be brought under some form of social control. What this represents, of course, is an alternative version of the Meidner plan for wage-earner funds, against which the Swedish bourgeois parties mobilised so effectively in the late 1970s. However, pension-fund reform is a necessary but not sufficient condition of socialisation and a new fiscal and legal framework for the political economy, e.g. global capital controls, would also be required in order to prevent financial globalisation from undermining the trend towards socialised accumulation. Similarly, all citizens would need to be covered by such funds, requiring pension reforms much more far reaching than those introduced by New Labour, for instance (Ward, 2000). ${ }^{2}$ If this were to occur, of course, then 'pension fund' might become a misnomer with 'endowment fund' being a preferable alternative (cf. Unger, 1998: 205). Nevertheless, with such reorganisations in place, Blackburn envisages that a proper system of stakeholder welfare would emerge, one less vulnerable than the welfare state to capital flight and taxpayer revolts. Blackburn (1999: 63) represents this as a synthesis of private and collective property rights.

So, in answer to the obvious and legitimate question 'How do we wrestle control of substitutables from private hands?', the most obvious 
solution is through the investment and gradual takeover of the companies and trusts who presently control such assets by democraticallycontrolled endowment funds. However, unless the new political economy that Blackburn mentions also incorporates Green taxes, then there is no incentive for the fundholders to be any more environmental then existing pension-fund managers. The ideal to work towards would be something like the following. Field $X$ has been earmarked for the development of a Conservation Park that would charge for research into natural habitats; field $Y$ has been earmarked for the construction of a car park. In the absence of Green taxes, the investment decision will flow in the direction of whichever plan promises the greatest returns. But with Green taxes, globally regulated, that take full account of all externalities, then the taxes on field $Y^{\prime}$ 's development will have to be high enough to subsidise the lower taxes on field $X^{\prime}$ 's development, making the former less attractive to investors. So, an ecosocial regime (i.e. the shift towards socialised capital through pension-fund reform) requires Green taxes if it is to be sustainable, and Green taxes require an ecosocial regime in order to secure their legitimacy and ensure that they are not interpreted as statist intrusions into the sphere of private accumulation.

Of course, the system of taxation is likely to alter depending upon the nature of the sustitutable in question. In the case of fossil fuels, for instance, taxation could fall most heavily on those activities which, while being dependent upon fossil fuels, are in no way concerned with their eventual substitution. This is what would distinguish an ecosocial property regime from, say, the dividend scheme operating in Alaska where oil from Prudhoe Bay is distributed to all Alaskan residents on an annual and egalitarian basis (Fitzpatrick, 1999a: 147-9). Although the Alaskan scheme combines some of the benefits of both collective and private ownership, it is not based upon a sustainable welfare index and so has few ecological credentials. Nevertheless, the same principle could be made to serve more sustainable objectives if the political will were in place.

In conclusion, the essential point of this long argument can be stated as follows. Helping the present poor requires something much more ambitious then the tax-and-spend redistribution usually favoured by social democrats. It requires a property regime based upon the socialisation of substitutable goods and Green taxation that yields a social dividend representing the private return on the collective ownership of the environment. This regime would assist in the transformation towards a post-productivist ethic of reproductive values that helps to create higher levels of sustainability than at present and so to reduce (and hopefully to eventually eliminate) the numbers of the future poor. Therefore the problem of transition is less between the present and future and more 
between those who do and do not support the current concentration of wealth in relatively few hands.

\section{Conclusion}

We began by arguing that a theory of intergenerational justice should be based upon contractualism, though with some reference to the notion of an intergenerational community. This yielded a low-low approach that treats future generations seriously, but which permits the utilisation of resources if the long-term aim is the transformation of our sources of value. Four principles of what I called sustainable justice were outlined and two rules (the Non-Futility and Deferred Enhancement Rules) were introduced as means of guiding the convergence of sustainability and distributive justice over the course of time. I concluded by suggesting that the ultimate conflict is less between the present and future than between those who do and those who do not recognise the claims of social justice, whether intra- or intergenerationally. To this end, I argued that the problem of present and future poverty can be addressed by exploring the prospects for an alternative property regime based upon the socialisation of substitutable goods, the ISEW, Green taxes, global regulation and the democratic control of endowment funds. BI and pensionfund reform might be regarded as more short-term policies conducive to these ends.

So, have we countered the arguments of Beckerman and Pasek? Let us revisit their syllogism, mentioned at the start of the chapter.

1 It is probably true that future generations cannot be said to have any rights with respect to ourselves, since they do not yet exist to claim such rights. We could imagine ourselves making claims on their behalf, but if we did so by applying a discount rate of 0 per cent, then this requires us to a weight to their rights equal to ours; a discount rate of less than 0 per cent implies that their rights count for less than ours, which seems to contradict the meaning of a 'right'.

2 However, although a theory of justice implies rights, rights do not have to inhabit each and every aspect of that theory. Justice also implies obligations and obligations can derive from the power we hold vis-à-vis the vulnerable. Future generations are vulnerable with respect to ourselves because we can harm them by bequeathing levels of autonomy to which we ourselves would not assent. To argue that we cannot harm (or benefit) the future is like arguing that we have not been harmed (or benefited) by the past. Certainly, it is difficult to determine the criteria of harm, but we can say with some confidence 
that harm is performed when demonstrable principles of justice, to which all rational and autonomous beings should agree, are ignored. Nor is it impossible that we would harm future generations by leaving them a pollution-free and resource-plenty environment - our equivalent of burning witches with good intentions - but the current evidence (on ecological degradation and its implications for human well-being) suggests otherwise.

Beckerman and Pasek therefore object not so much to future generations lacking rights, but to their inability to reciprocate any benefits that we bequeath. Yet this is a narrow view of reciprocity that neglects deontological conceptions of justice where we ought to perform certain acts because it is right, irrespective of whether those who receive the consequences of those acts can pay us back or not. Justice is concerned with the distribution of benefits and burdens but, as argued in Chapter 2, this does not mean that benefits and burdens have to balance exactly on each and every occasion. The present generation cannot be expected to carry all the burdens (since the discount rate ought not to be 0 per cent), merely those that facilitate a future level of autonomy to which all generations, across a given timescale would contract in the original position.

3 Therefore, the second premise fails and so the interests of future generations can be protected or promoted within the framework of a theory of justice.

This by no means exhausts the full range of Beckerman and Pasek's arguments, but it is enough to suggest that sustainability and distributive justice possess far stronger implications for one another than they and many others seem to imagine.

\section{Notes}

1 For simplicity's sake I am using a 0-10 scale and I am assuming no overlap between generations. Nor am I going to discuss whether the discount rate is constant or non-constant.

2 Though Blackburn is certainly not suggesting that these could ever substitute for an adequately financed basic state pension. 